\title{
Climatic niche and neutral genetic diversity of the six Iberian pine species: a retrospective and prospective view
}

\author{
A. SOTO, J. J. ROBLEDO-ARNUNCIO, S. C. GONZÁlEZ-MARTíneZ, P. E. SMOUSE \\ and R. ALÍA \\ Departamento de Sistemas y Recursos Forestales, CIFOR-INIA, Ctra. de La Coruña km 7.5, 28040 Madrid, Spain, \\ Universidad Politécnica de Madrid, G.I. Genética y Fisiología Forestal, Ciudad Universitaria s/n. 28040 Madrid, Spain, \\ Unidad Mixta INIA-UPM de Genómica y Ecofisiología Forestal, 28040 Madrid, Spain, Department of Ecology, \\ Evolution \& Natural Resources, Rutgers University, New Brunswick, NJ 08901, USA
}

\begin{abstract}
Quaternary climatic fluctuations have left contrasting historical footprints on the neutral genetic diversity patterns of existing populations of different tree species. We should expect the demography, and consequently the neutral genetic structure, of taxa less tolerant to particular climatic extremes to be more sensitive to long-term climate fluctuations. We explore this hypothesis here by sampling all six pine species found in the Iberian Peninsula (2464 individuals, 105 populations), using a common set of chloroplast microsatellite markers, and by looking at the association between neutral genetic diversity and species-specific climatic requirements. We found large variation in neutral genetic diversity and structure among Iberian pines, with cold-enduring mountain species (Pinus uncinata, $P$. sylvestris and $P$. nigra) showing substantially greater diversity than thermophilous taxa ( $P$. pinea and $P$. halepensis). Within species, we observed a significant positive correlation between population genetic diversity and summer precipitation for some of the mountain pines. The observed pattern is consistent with the hypotheses that: (i) more thermophilous species have been subjected to stronger demographic fluctuations in the past, as a consequence of their maladaptation to recurrent glacial cold stages; and (ii) altitudinal migrations have allowed the maintenance of large effective population sizes and genetic variation in cold-tolerant species, especially in more humid regions. In the light of these results and hypotheses, we discuss some potential genetic consequences of impending climate change.
\end{abstract}

Keywords: chloroplast DNA diversity, climatic change, Holocene, Iberian Peninsula, phylogeography, Pinus

\section{Introduction}

Climate change is triggering vegetation range-shifts in many parts of the world and we can anticipate increasing impacts for the future. In Europe, these changes are likely to result in the northward shift of Mediterranean ecosystems, currently recognized as plant biodiversity hotspots (Myers et al. 2000), into the comparatively species-poor Euro-Siberian region (IPCC 2001; Thuiller et al. 2005). Individual species responses to such changes will depend on ecological and evolutionary factors such as niche breadth, colonization and competitive ability, phenotypic plasticity, and adaptability. Considerable information is now available on gene flow (at the local and regional scale), long distance migration, and paleogeographic history (Taberlet et al. 1998; Hewitt 2000; Liepelt et al. 2002; Petit et al. 2003), and on how such factors have shaped the current distribution of 
genetic diversity in tree species (e.g. Newton ef al. 1999; Bucci et al. 2007). The combination of longevity, high intra-population genetic diversity and long-distance seed and pollen dispersal should make trees more resistant to extinction and loss of genetic diversity in changing environments than other plant species (Hamrick 2004). Tree species show substantial variation in their ecological requirements, however, and we should expect the demographic and genetic structure of taxa less tolerant to particular climatic extremes to be more sensitive to climate fluctuations.

Quaternary climatic fluctuations have left a historical footprint on the neutral genetic population structure and diversity of existing populations of many tree species (Comes \& Kadereit 1998; Hewitt 2000) that should provide some insight into the interaction between climatic niche and climate change sensitivity, relative to predicting future changes (Petit et al. 2008). Under the a priori hypothesis that species-specific climatic requirements have influenced long-term demographic processes, we would expect variation in current levels of neutral genetic diversity (reflecting those demographic processes) across species and some degree of association of genetic diversity levels with current climatic range. In particular, given the mild pre-Quaternary conditions and the prevalence of cold stages throughout the Pleistocene in Europe (Anderson \& Borns 1994), populations of warm-demanding species would have suffered stronger demographic fluctuations during glaciations and, consequentially, more intense genetic erosion than cold-tolerant species.

Several genetic-marker-based methods have been used to investigate Holocene migration routes in diverse organisms, showing that hotspots of genetic diversity are associated with glacial refugia in the Iberian Peninsula, Italy and the Balkans (e.g. Taberlet et al. 1998; Petit et al. 2003; Gómez \& Lunt 2007). Still, detailed analysis of major glacial refugial regions including the low-latitude limit ('rear edge') of species ranges (the 'refugia within the refugia') is still lacking (Hampe \& Petit 2005; Gómez \& Lunt 2007). In addition, few studies are based on plant communities or complete species clades (e.g. Fady-Welterlen 2005; Médail \& Diadema 2009). Multi-species comparative studies of genetic diversity provide powerful inference on the interplay among climatic changes, species-specific ecological requirements and long-term demographic dynamics (Alvarez et al. 2009). Here, we adopt a multispecies approach, sampling all six pine species found in the Iberian Peninsula (2464 individuals, 105 populations) with a common set of chloroplast microsatellite markers. By studying the level and distribution of neutral genetic diversity of congenerics that show similar life-history traits but diverse adaptations to local environments across their Iberian ranges, and by examining the climatic correlates of observed neutral population genetic structure, we can shed some light on species-specific demographic responses to past climate changes and on the demographic and genetic effects to be expected from future climate changes. Neutral genetic variation obviously does not reflect adaptive differentiation, but it allows inference about the longterm demography of different species, which can be compared against climatic niche correlates.

Pine species are important components of many natural ecosystems across the Mediterranean (Barbéro et al. 1998), and their demographic and genetic dynamics may therefore have community-level consequences (Whitham et al. 2006). Six pine species are native to the Iberian Peninsula (Pinus halepensis Mill. $P$. pinea L., P. pinaster Ait., P. nigra Arn., P. sylitestris L. and $P$. uncinata Ram.); the fossil record shows their presence throughout the Holocene (Carrión ef at. 2003; García-Amorena ef al. 2007). These species belong to two different clades of Eurasian pines (Price et al. 1998; Wang et al. 1999): the Mediterranean clade (=Pinaster; see Gernandt ef at. 2005) (P. halepensis, P. pinea and $P$. pinaster) and the sylvestres clade ( $P$. nigna, $P$. sylvestris and $P$. uncinata). This sextet of species presents marked differences in ecological requirements (Tapias et al. 2004). Within the Iberian Peninsula, P. pinaster has the broadest ecological niche (from sea level to high altitude, a range of $1900 \mathrm{~m}$, and in different soil types); Pinus nigra also has a broad ecological niche (though being less tolerant of high temperature and drought than P. pimaster); the other species, despite large current distribution ranges, are confined to comparatively narrow environments, $P$. halepensis and $P$. pinea in the Mediterranean bioregion and $P$. uncinata at high-mountain timberline. Previous studies with organelle markers have generally shown higher levels of neutral genetic diversity for Eurasian $P$. sylvestris and $P$. nigra (Robledo-Arnuncio ef al. 2005; Afzal-Rafii \& Dodd 2007) than for the three Mediterranean pine species (Bucci et al. 1998, 2007; Vendramin et al. 2008). These differences are also apparent with allozyme protein markers, with $P$. syloestris having high levels of genetic variation (Prus-Glowacki ef at. 2003), Pinus pinaster intermediate levels (Salvador ef al. 2000) and $P$. pinea very low polymorphism (Fallour ef at. 1997), the latter probably due to a severe and prolonged demographic bottleneck (Vendramin et al. 2008). However, these studies did not use the same biochemical or molecular markers in all cases and none was based on an exhaustive sample of all six species across a wide shared range with a common Holocene history, such as the Iherian Peninsula, thus complicating comparative inference. 
We report here the levels of neutral genetic diversity and differentiation of an extensive sample of native populations of all six Iberian pine species, based on a common set of chloroplast microsatellite (cpSSR) markers. Their moderate levels of polymorphism and their non-recombinant, uniparentally-inherited nature make cpSSRs useful markers for biogeographic studies (Provan et al. 2001). The use of a common set of markers is particularly valuable for cross-species comparisons, although such studies remain very rare (but see Price ef al. 1998; Alvarez ef at. 2009). Two specific questions are considered here: (i) How different are the levels of neutral genetic diversity and population genetic differentiation across ecologically-divergent (albeit closelyrelated) pine species in the lberian Peninsula? (ii) Is neutral genetic diversity of Iberian pines correlated with species-specific climatic requirements? The answer to such questions should inform any discussion of past demographic and genetic history, as well as the likely genetic consequences of impending climate change.

\section{Materials and methods}

\section{Plant material and molecular methods}

A total of 2464 individuals from 105 populations were sampled, covering the Iberian range of the six native pine species (Supporting Information Fig. S1) and distributed as follow (\# populations, \# individuals): P. halepensis $(13,312)$, P. pinea $(5,114), P$. pinaster $(38$, 892), P. nigra $(14,326), P$. sylvestris $(30,706)$ and $P$. uncinata $(5,114)$. A special effort was made to include only native populations, based on fossil and/or historical records (detailed location maps of native pine populations for each species are available on request). Sampling was designed to cover the full ranges of the species in Spain, especially in mountainous areas, where physiographic heterogeneity and steep gradients of rainfall and temperature result in varied ecological conditions. The relative genetic isolation of the Iberian Peninsula from other glacial refugia (see, for instance, Cheddadi ef al. (2006) for P. sylvestris) makes it an adequate setting for the detection of genetic signatures of regional demographic dynamics.

Sampled populations of the six Iberian pines occur across a Mediterranean-Eurosiberian gradient, characterized by a decrease of the drought period and an increase of frost incidence with increasing altitude and latitude (see Table S1 in online Supporting Information). Pinus halepensis is found in warm Mediterranean climates, with the highest mean temperatures ( $T: 14,3 \pm$ $1.8^{\circ} \mathrm{C}$ ) and a prolonged dry period (annual rainfall, $P$, of $492 \pm 122 \mathrm{~mm}$ ). Pinus uncinata populations, by contrast, are found in the coldest environments
(T: $7.8 \pm 1.3^{\circ} \mathrm{C}$ ) and the shortest dry period during the summer $(P: 816 \pm 153 \mathrm{~mm})$. The other species, $P$. pinea (T: $12.9 \pm 0.8^{\circ} \mathrm{C} ; P: 401 \pm 16 \mathrm{~mm}$ ), $P$. pinaster $(T: 12.5 \pm$ $1.9^{\circ} \mathrm{C} ; \quad P: 572 \pm 199 \mathrm{~mm}$ ), P. nigra (T: $10.6 \pm 2.4{ }^{\circ} \mathrm{C}$; $P: \quad 682 \pm 179 \mathrm{~mm}$ ) and $P$. sylvestris (T: $8.8 \pm 1.9^{\circ} \mathrm{C}$; $P$ : $720 \pm 186 \mathrm{~mm}$ ), are found between these extremes. Populations of $P$. pinaster and $P$. nigra can grow in a large range of climatic conditions, including cold continental areas, whereas $P$. pinea and $P$. halepensis grow in areas characterized by comparatively narrow warm niches. From each population, we randomly selected 24 trees, spaced at least $50 \mathrm{~m}$ apart, from which needles or seeds were collected and stored at $4{ }^{\circ} \mathrm{C}$ until DNA isolation.

Needle (collected in the field) or seedling tissue (obtained from germinated seeds) were ground in liquid nitrogen, and total DNA was extracted using Dellaporta et al. (1983) and Doyle \& Doyle (1990) protocols for needles and seedlings, respectively. Four microsatellite regions (Pt15169, Pt36480, Pt71936, Pt87268; Vendramin ef al. 1996) of the chloroplast genome were amplified in all six pine species. An additional locus (Pt30204) was screened in all species but $P$. halepensis, and one more (Pt1254) in all species but $P$. halepensis and $P$. pinea. Protocols for polymerase chain reactions (PCR) and fragment sizing are described in Gómez et al. (2005). Fragment sizes obtained in the Li-Cor 4200 Series and ALF Express automatic sequencers were standardized using samples of known size from all six species. Most genotypic data were specifically generated for this study, though some within-species partial results, based on a small number of Iberian populations or loci, can be found in previous works (Gómez et at. 2005 for P. halepensis and P. pinaster, Heuertz et al. 2009 for $P$. uncinata, Robledo-Arnuncio ef al. 2005 for $P$. sylvestris, Vendramin et al. 2008 for P. pintea).

\section{Genetic diversity and differentiation estimates}

Genetic diversity estimates were computed for each of the six cpSSR regions separately, and for haplotypes defined from the combination of: (i) the four cPSSR regions assessed in all species; and (ii) the five and (iii) six cpSSR regions assessed in all species except, respectively, $P$. halepensis and $P$. halepensis and $P$. pintea. In this way, it was possible to make all-six-species comparisons using the common set of four markers and fiveand four-species comparisons with additional genetic resolution. The following species-level genetic diversity parameters were computed after pooling data from all populations within each species: the observed number of alleles $(n 100)$ and haplotypes ( $n h 100)$, standardized to a sample size of 100 , using the rarefaction method described in El Mousadik \& Petit (1996), and the effective 
numbers of alleles $\left(n_{\mathrm{e}}\right)$ and haplotypes $\left(n h_{\mathrm{e}}\right)$, defined as the inverses of the unbiased probability of allelic or haplotypic identity on the total set of alleles or haplotypes of each species (Nielsen et al. 2003).

Standard errors were computed by bootstrapping individuals within species 1000 times. It would not be correct to perform a non-parametric permutation test of diversity differences between species pairs, since each pair of samples (species) will be non-identical (genetic pools with different haplotypic spectra) even under the null hypothesis of equal diversity. For this reason, a bootstrap-based test for comparing two samples was conducted in three steps: (1) draw a random resample of individuals with replacement from the species with higher observed diversity and a separate random resample from the second species, and compute the difference in diversity parameters between the first and the second group; (2) repeat the first step 1000 times; and (3) construct the bootstrap distribution of the difference between diversity parameters, rejecting the null hypothesis of equal diversity if the $\alpha$-th percentile of the bootstrap distribution is larger than zero, with $\alpha$ being the individual comparison significance level (calculated using a Bonferroni correction for multiple comparisons with experiment-wise 0.05 significance).

Population-level genetic diversity was also assessed for each species by estimating the mean number of haplotypes per population, adjusted to a sample size of 15 (nhp15) and the mean effective number of haplotypes per population $\left(n h p_{\mathrm{e}}\right)$. In this case, haplotypic diversity was computed based on the four common cPSSR haplotypes only, since the number of five- and six-locus haplotypes per population was so large that in many cases all trees within a given population carried a unique haplotype, resulting in important small sample size biases for haplotypic richness measures and infinite values for the effective number of haplotypes.

To test for genetic structuring among populations within species, haplotypic $F_{\mathrm{ST}}, R_{\mathrm{ST}}$ and $D$ were computed. $F_{\mathrm{ST}}$ and $R_{\mathrm{ST}}$ are classical measures of genetic structure, which we calculated using an AMOVA (Excoffier et al. 1992) with inter-haplotypic distance metric defined as the number of different cPSSR regions (for $F_{\mathrm{ST}}$ ) and the sum of squared size differences (for $R_{\mathrm{ST}}$ ). By incorporating a step-wise microsatellite mutation model (SMM), $R_{\mathrm{ST}}$ may potentially reveal phylogeographic patterns (Hardy et al. 2003) (but notice that the fragments do not always follow a strict SMM; see Supporting Information Appendix S2). Following Hardy et al. (2003), a randomization test based on 10000 permutations of allele sizes among allelic states was used to determine whether stepwise-like mutations contributed to genetic differentiation. Unlike $F_{\mathrm{ST}}$, Jost's $D$ provides a measure of actual differentiation of haplotypic frequencies among populations that is mathematically independent of within-population diversity (Jost 2008), which is useful when comparing genetic differentiation across species with contrasting diversity levels. We used the nearly unbiased estimator of $D$ described in Jost (2008), based on Nei \& Chesser (1983) diversity estimators.

Differences in genetic structure between species pairs were tested by bootstrapping over populations in three steps: (1) assuming that populations are independent, draw a random resample of populations with replacement from the species with higher differentiation and a separate random resample from the second species, and compute the difference in genetic structure parameters between the first and the second group; (2) repeat the first step 1000 times; and (3) construct the bootstrap distribution of the difference between genetic structure parameters, rejecting the null hypothesis of equal structure if the $\alpha$-th percentile of the bootstrap distribution is larger than zero, with $\alpha$ being the individual comparison significance level (calculated using a Bonferroni correction for multiple comparisons with experiment-wise 0.05 significance).

\section{Correlation among population genetic diversify and climatic variables}

Three climatic variables were considered: mean annual (T) and minimum of the coldest month (MTC) temperatures, and summer rainfall $(P s)$. These variables have a strong link with the physiology and growth of plant species in the Mediterranean (Thompson 2005) and have previously been used to model their distribution across Europe and the Iberian Peninsula (Thuiller et al. 2005; Benito Garzón et al. 2008). In addition, they are important descriptive variables for the present distribution of the six pine species in Spain 3rd Spanish National Forest Inventory: grid of $1 \times 1 \mathrm{~km}$, data obtained in 1997-2006; BDB 2006; Sánchez de Ron \& García del Barrio, unpublished data), as revealed by a Maximum entropy model of species distribution with jackknife test of climatic variable importance (using the Maxent software by Phillips et al. 2006; see Supporting Information Fig. S2). Climatic data were obtained for each population from a climatic model of the lberian Peninsula (Gonzalo 2007) (Supporting Information Table S1).

The relationship between genetic diversity within populations (nhp15 and $n h p_{\mathrm{e}}$ ) and population climatic variables (T, MTC and $P s$ ) was analyzed using linear regression, with a parallelism test of regression lines (Milliken \& Johnson 2001) for determining significant differences in independent terms $\left(\alpha_{i}\right)$ and regression coefficients $\left(\beta_{i}\right)$ between species. In cases where the 
regression coefficients were significantly different between species, we conducted contrasts of slopes ( $t$-test) among each pair of species. All 105 populations from the six pines were used for this analysis.

\section{Results}

\section{Genetic diversity and differentiation of Iberian pines}

The six Iberian pine species differed greatly in levels of genetic diversity (Tables 1 and 2; see also Table S2 in Supporting Information). Four of the cpSSR markers (Pt15169, Pt30204, Pt36480 and Pt87268) were monomorphic in $P$. pinea and one ( $\mathrm{Pt} 36480$ ) in $P$. halepensis, while all six were polymorphic in the other four species. Chloroplast microsatellite (cpSSR) fragment sizes overlapped among species, except for Pt15169, which had a 4-bp difference between $P$. halepensis-pinea-pinaster-nigra and $P$. sylvestris-uncinata, which could thus be used to discriminate these two groups of species. Variation in size among cPSSR variants was due, in most cases, to differences in the number of repeats of the microsatellite motif, as revealed by sequencing of common variants in all six pine species see Supporting Information
Appendix 52). Number of repeats was roughly similar for all loci in sequenced trees. Moreover, variant sizes were similar among species within each locus, and we did not find any correlation between microsatellite length and genetic diversity at the species level (data not shown). The most variable locus, in terms of $n 100$ and $n_{\mathrm{e}}$, was different for each species.

Focusing on the set of four cPSSR regions genotyped in all species, a total of 273 haplotypes were observed across all six pines, with substantial specific variation, ranging from only two haplotypes in $P$. pinea to a maximum of 98 in P. sylvestris. Most haplotypes $(\sim 98 \%)$ were species-specific. Four and zero haplotypes, respectively, were shared among reportedly interfertile $P$. sylvestris/P. uncinata (Wachowiak \& Prus-Glowacki 2008) and $P$. halepensis/P. pinaster (Schütt 1959) pairs (data not shown). Shared haplotypes between $P$. sylvestris and $P$. uncinata based on four cPSSR regions, however, turned out to be different when the number of assessed regions increased to six, ruling out the possibility that they were the result of recent natural hybridization. The most frequent haplotypes (21 haplotypes with a frequency greater than 0.05 in at least one of the species) had a collective frequency of $54.5 \%$ (Table 1) whereas

Table 1 Frequency of most common haplotypes across the six Iberian pine species. Haplotypes were defined as unique combinations of size variants at four chloroplast microsatellites (Pt15169, Pt36480, Pt71936 and Pt87268)

\begin{tabular}{|c|c|c|c|c|c|c|c|c|}
\hline \multirow[b]{2}{*}{ Code } & \multirow[b]{2}{*}{ Haplotype } & \multirow[b]{2}{*}{ Tally } & \multicolumn{6}{|c|}{ Within-species frequency } \\
\hline & & & $\begin{array}{l}\text { Pinus } \\
\text { halepensis }\end{array}$ & $\begin{array}{l}\text { Pinus } \\
\text { pinea }\end{array}$ & $\begin{array}{l}\text { Pinus } \\
\text { pinaster }\end{array}$ & $\begin{array}{l}\text { Pinus } \\
\text { nigra }\end{array}$ & $\begin{array}{l}\text { Pinus } \\
\text { sylvestris }\end{array}$ & $\begin{array}{l}\text { Pinus } \\
\text { whinata }\end{array}$ \\
\hline H4L033 & $114,140,147,172$ & 270 & 0.865 & & & & & \\
\hline H4L044 & $114,145,143,163$ & 173 & & 0.020 & 0.216 & & & \\
\hline H4L040 & $114,145,142,163$ & 108 & & 0.980 & 0.011 & & & \\
\hline H4L252 & $128,144,146,165$ & 89 & & & & & 0.133 & \\
\hline H4L065 & $115,145,143,163$ & 77 & & & 0.097 & & & \\
\hline H4L231 & $127,144,146,165$ & 72 & & & & & 0.108 & \\
\hline H4L043 & $114,145,143,162$ & 58 & & & 0.073 & & & \\
\hline H4L235 & $127,144,147,165$ & 43 & & & & & 0.064 & \\
\hline H4L205 & $126,144,146,165$ & 42 & & & & & 0.061 & 0.009 \\
\hline H4L129 & $118,145,148,167$ & 41 & & & & 0.134 & & \\
\hline H4L256 & $128,144,147,165$ & 40 & & & & & 0.060 & \\
\hline H4L070 & $115,145,144,163$ & 40 & & & 0.051 & & & \\
\hline H4L121 & $118,145,147,166$ & 38 & & & & 0.124 & & \\
\hline H4L122 & $118,145,147,167$ & 38 & & & & 0.124 & & \\
\hline H4L232 & $127,144,146,166$ & 38 & & & & & 0.057 & \\
\hline H4L128 & $118,145,148,166$ & 33 & & & & 0.107 & & \\
\hline H4L168 & $124,144,144,164$ & 14 & & & & & & 0.126 \\
\hline H4L167 & $124,144,143,164$ & 13 & & & & & & 0.117 \\
\hline H4L155 & $123,144,144,166$ & 10 & & & & & 0.001 & 0.081 \\
\hline H4L154 & $123,144,144,165$ & 9 & & & & & & 0.081 \\
\hline H4L157 & $123,144,145,165$ & 6 & & & & & & 0.054 \\
\hline H4L173 & $124,144,145,166$ & 6 & & & & & & 0.054 \\
\hline \multicolumn{2}{|c|}{ Cumulative fraction } & 0.545 & 0.865 & 1.000 & 0.448 & 0.489 & 0.484 & 0.522 \\
\hline \multicolumn{2}{|c|}{ Total \# of haplotypes } & 106 & 16 & 2 & 86 & 51 & 98 & 29 \\
\hline
\end{tabular}


Table 2 Chloroplast haplotypic richness and diversity for the six Iberian pine species. Species-level estimates were obtained after pooling populations within each species. Population-level estimates are averages across populations within species. Haplotypic diversity values with at least one common upper-case letter are not significantly different across species (experiment-wise $\alpha=0.05$ )

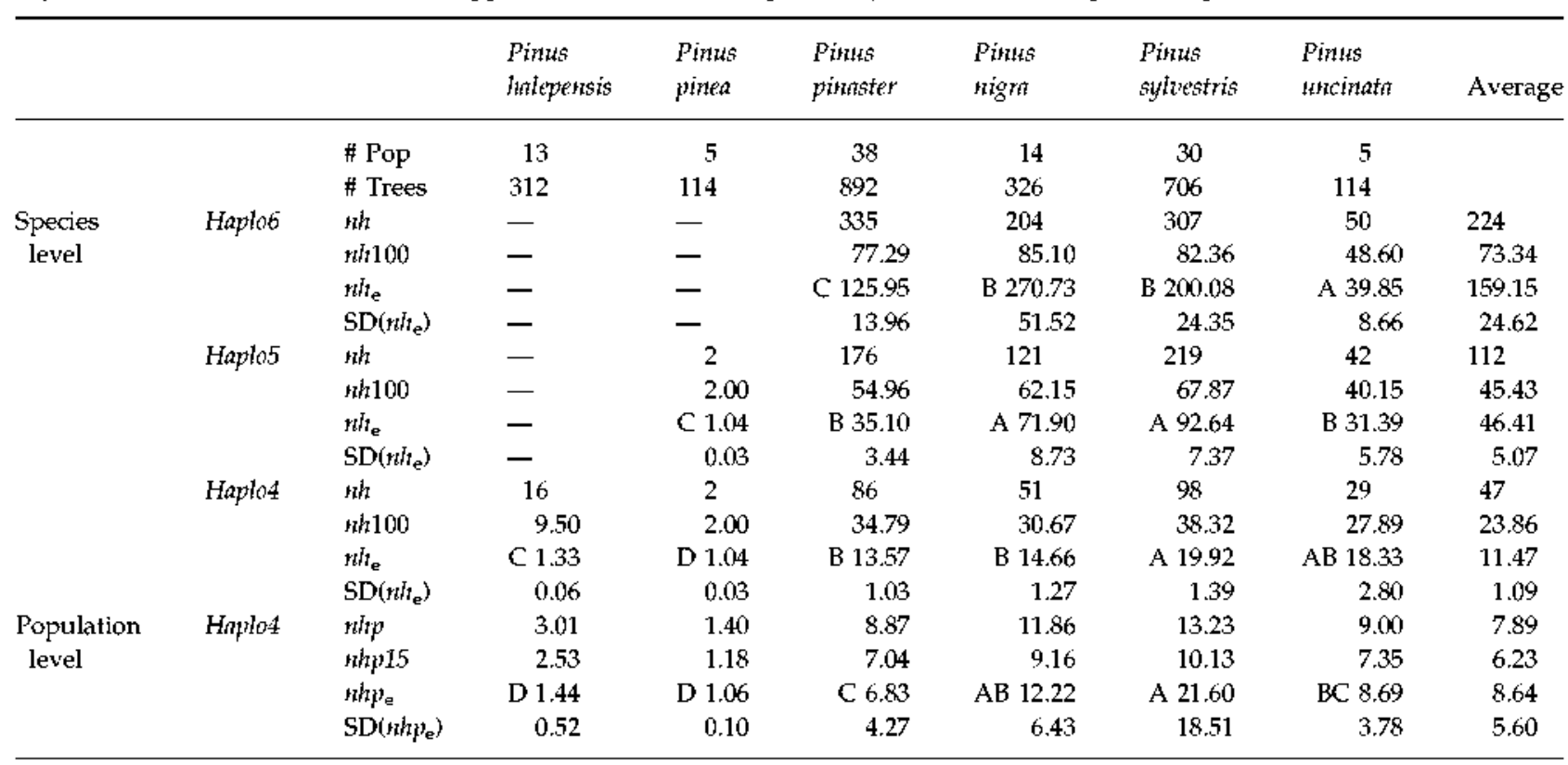

\# Pops, number of populations sampled; \# Trees, number of individuals sampled; $n h$, observed number of haplotypes; $i h 100$, observed number of haplotypes, corrected for a sample size of $100 ; n h_{e}$, effective number of haplotypes; SD (nhe), standard deviation of the effective number of haplotypes; nhp15, observed number of haplotypes per population, corrected for a sample size of 15; nht effective number of haplotypes per population; SD (nhp $p_{\mathrm{e}}$, standard error of $n h p_{e}$, Haplo4, haplotypes defined at Pt15169, Pt36480, Pt71936 and Pt87268 cpSSR regions; Haplo5, haplotypes defined at the same cpSSR regions as Haplo4 plus Pt30204; Haplo6, haplotypes defined at the same cPSSR regions as Haplo5 plus Pt1254.

singletons (of which there were 106) represented a collective frequency of only $4.6 \%$. The frequencies of the most abundant haplotype of each species differed greatly, being over $85 \%$ in $P$. halepensis and $P$. pintea, the two species with lower genetic diversity, and below $25 \%$ in the more polymorphic $P$. pinaster, $P$, nigra, $P$. sylivestris or $P$. uncinata.

Haplotypic diversity was substantially smaller in thermophilous $P$. halepensis and $P$. pinea than in the other species, both at the species and population levels, while mountain species $P$. nigna and $P$. syloestris showed the largest diversity values (Table 2). For instance, $P$. sylvestris showed effective numbers of haplotypes at the species $\left(n h_{\mathrm{e}}\right)$ and population $\left(n h p_{\mathrm{e}}\right)$ levels that were about 20 -fold greater than the corresponding values for $P$. pinea, considering four-locus haplotypes. Pinus pinaster and $P$. uncinata had intermediate levels of haplotypic diversity, relative to the other species, not significantly different from each other at the population level but significantly larger for $P$. pinaster at the species level (when considering six-locus haplotypes; Table 2). Haplotypic richness measures ( $n$ h100 and whp15) ranked species in the same order as haplotypic diversity measures $\left(n h_{\mathrm{e}}\right.$ and $\left.n h p_{\mathrm{e}}\right): P$. sylvestris $>$ P. nigna $>$ P. uncinata $>P$. pinaster $>P$. halepensis $>P$. pinea. A numerical anal- ysis showed that the unequal sample sizes were not a confounding factor in cross-species comparisons (see Supporting Information Appendix S1).

All species showed significant levels of population differentiation, except $P$. pintea, which exhibited very limited haplotypic variation and no population divergence (Table 3). The scattered dwarf mountain pine, $P$. uncinata, and the ecotypically diverse and also highly fragmented maritime pine, $P$. pinaster, showed the largest $F_{\mathrm{ST}}$ values $(>0.20$, not significantly different from each other), followed by considerably lower values ( $F_{\mathrm{ST}}<0.12$, considering four-locus haplotypes) for P. nigra and $P$. sylvestris and for the low-diversity P. halepensis. Estimated variances of $F_{\mathrm{ST}}$ were large, thus limiting the statistical power of multispecies comparisons, but some of the differences in the level of genetic structure among species were significant. The population differentiation of $P$. pinaster was notably stronger than that of any other species, except $P$. uncinata. Noteworthy, highly scattered timberline $P$. uncinata exhibited stronger differentiation than $P$. sylvestris, which is also scattered but is ecologically more diverse and wider spread (Table 3).

Higher values of $R_{\mathrm{ST}}$ than $F_{\mathrm{ST}}$ (following Hardy et al. 2003) were observed only for $P$. syluestris, when 
Table 3 Among-population haplotypic differentiation $\left(F_{\mathrm{ST}}, R_{\mathrm{ST}}\right.$ and $\left.D\right)$ within each of the six Iberian pine species. All values except those marked (NS) are significantly different from zero $(P<0.05)$. Differentiation values with at least one common upper-case letter are not significantly different across species (experiment-wise $\alpha=0.05$ ). Bold $R_{\mathrm{ST}}$ values are significantly $(P<0.05)$ greater than the corresponding $F_{\mathrm{ST}}$ values (Hardy et al. 2003)

\begin{tabular}{|c|c|c|c|c|c|c|c|}
\hline & Statistic & Pinus hatepensis & Pinus pinet & Pinus pinterster & Pints rigrt & Pinus sylvestris & Pinus uncinata \\
\hline \multirow[t]{3}{*}{ Haplo4 } & $F_{\mathrm{ST}}$ & $0.072 \mathrm{BC}$ & 0.014 NS C & $0.292 \mathrm{~A}$ & $0.117 \mathrm{~B}$ & $0.045 \mathrm{CB}$ & $0.358 \mathrm{AB}$ \\
\hline & $R_{\mathrm{ST}}$ & $0.079 \mathrm{BC}$ & 0.014 NS C & $0.172 \mathrm{~A}$ & $0.146 \mathrm{AB}$ & $0.161 \mathrm{ABC}$ & $0.448 \mathrm{AB}$ \\
\hline & $D$ & $0.023 \mathrm{C}$ & 0.000 NS C & $0.676 \mathrm{~A}$ & $0.368 \mathrm{~B}$ & $0.362 \mathrm{~B}$ & $0.782 \mathrm{~A}$ \\
\hline \multirow[t]{3}{*}{ Haplo5 } & $F_{\mathrm{ST}}$ & - & 0.014 NSC & $0.259 \mathrm{~A}$ & $0.079 \mathrm{BC}$ & $0.038 \mathrm{BC}$ & $0.293 \mathrm{AB}$ \\
\hline & $R_{\mathrm{ST}}$ & - & 0.014 NS C & $0.182 \mathrm{~A}$ & $0.091 \mathrm{BC}$ & $0.129 \mathrm{AB}$ & $0.385 \mathrm{AB}$ \\
\hline & $D$ & - & $0.001 \mathrm{NS} \mathrm{E}$ & $0.763 \mathrm{D}$ & $0.518 \mathrm{C}$ & $0.617 \mathrm{~B}$ & $0.900 \mathrm{~A}$ \\
\hline \multirow[t]{3}{*}{ Haplo6 } & $F_{\mathrm{ST}}$ & - & - & $0.221 \mathrm{~B}$ & $0.136 \mathrm{~A}$ & $0.070 \mathrm{C}$ & $0.322 \mathrm{AB}$ \\
\hline & $R_{\mathrm{ST}}$ & - & - & $0.173 \mathrm{~A}$ & $0.214 \mathrm{~A}$ & $0.191 \mathrm{~A}$ & $0.513 \mathrm{~A}$ \\
\hline & $D$ & - & - & $0.869 \mathrm{C}$ & $0.794 \mathrm{~B}$ & $0.811 \mathrm{~B}$ & $0.929 \mathrm{~A}$ \\
\hline
\end{tabular}

Haplo4, haplotypes defined at Pt15169, Pt36480, Pt71936 and Pt87268 cpSSR regions; Haplo5, haplotypes defined at the same cpSSR regions as Hiplo4 plus Pt30204; Haplo6, haplotypes defined at the same cpSSR regions as Haplo5 plus Pt1254.

considering four-locus haplotypes, and for P. syliestris, $P$. uncinata and $P$. nigra, when considering five or sixlocus haplotypes (Table 3), but not for any of the thermophilous Mediterranean pines ( $P$. pinaster, $P$. halepensis and $P$. pinea), indicating that significant phylogeographic structure in the region is found only in the mountain pine species. These results should be interpreted with some caution, however, given the very low genetic variation of $P$. halepensis and $P$. pintea, and given that even if homoplasy and imperfect step-wise mutation (we found two cases of indels within the SSR regions, see Supporting Information Appendix S2) seem to have very little influence on conifer cpSSR diversity measures based on haplotypic counts and effective haplotypic numbers, they can nevertheless confound phylogeographic structure detection (Navascués \& Emerson 2005).

The actual differentiation measure $D$ ranked species very similarly than $F_{\mathrm{ST}}$ and $R_{\mathrm{ST}}$, confirming the position of $P$. pinea and $P$. halepensis at the lower extreme of the differentiation spectrum, of $P$. uncinata and $P$. pinaster at the higher extreme, and of $P$. sylvestris and $P$. nigra in between (Table 3). As expected (Jost 2008), actual differentiation was substantially higher than $F_{\mathrm{ST}}$ for all but the minimally diverse species ( $P$. halepensis and $P$. pinea). In particular, $D$-values reached $\sim 90 \%$ for $P$. uncinat $a$ and $P$. pimaster and $\sim 80 \%$ for $P$. nign and P. syltestris, based on six-cpSSR haplotypes (Table 3).

\section{Correlation between genetic diversity within populations and climatic variables}

Within-population genetic diversity was significantly correlated with the three climatic variables considered (Fig. 1 and Supporting Information Table S3). In the case of the mean annual $(T)$ and minimum of the coldest month (MTC) temperatures, the correlations were negative and due to a species effect: populations of species with lower T and MTC (i.e. colder-tolerant species) exhibited significantly larger effective numbers of haplotypes ( $m p_{\mathrm{e}}$ ) and standardized numbers of haplotypes (nhp15) (Fig. 1; Supporting Information Table 53). The associations between genetic diversity and temperature variables were also negative for populations of individual species (except for P. pinea; data not shown), but the intraspecific effect was not significant (Supporting Information Table S3). In the case of the summer precipitation $\left(P_{s}\right)$, there was a significant populationwithin-species effect. In particular, nhpe and nhp15 showed a significant positive linear relationship with $P$ s in $P$. nign and P. uncimata, while there was a significant negative correlation in $P$. pinaster (Fig. 1; Table 4). Overall, correlations between genetic diversity within populations and the range of climatic variation can be summarized as: (i) higher genetic variation in Eurosiberian species, $P$. sylvestris and $P$. uncinata, relative to thermophilous pines, $P$. pintea and P. halepentsis; (ii) lower genetic variation in more Mediterranean, more summer-drought affected, populations within mountain species (though not significant for P. syloestris); (iii) lower genetic variation in more Eurosiberian populations within Mediterranean P. pinaster; and (iv) virtually no haplotypic variation within either $P$. pinea or $P$. halepensis, avoiding any potential association between genetic and climatic variables within these species.

\section{Discussion}

This paper presents new comparative data on neutral genetic diversity patterns across the six pine species present in a refugial area of high interest for phylogeographic studies, the Iberian Peninsula, using a common set of chloroplast DNA markers. There was large 

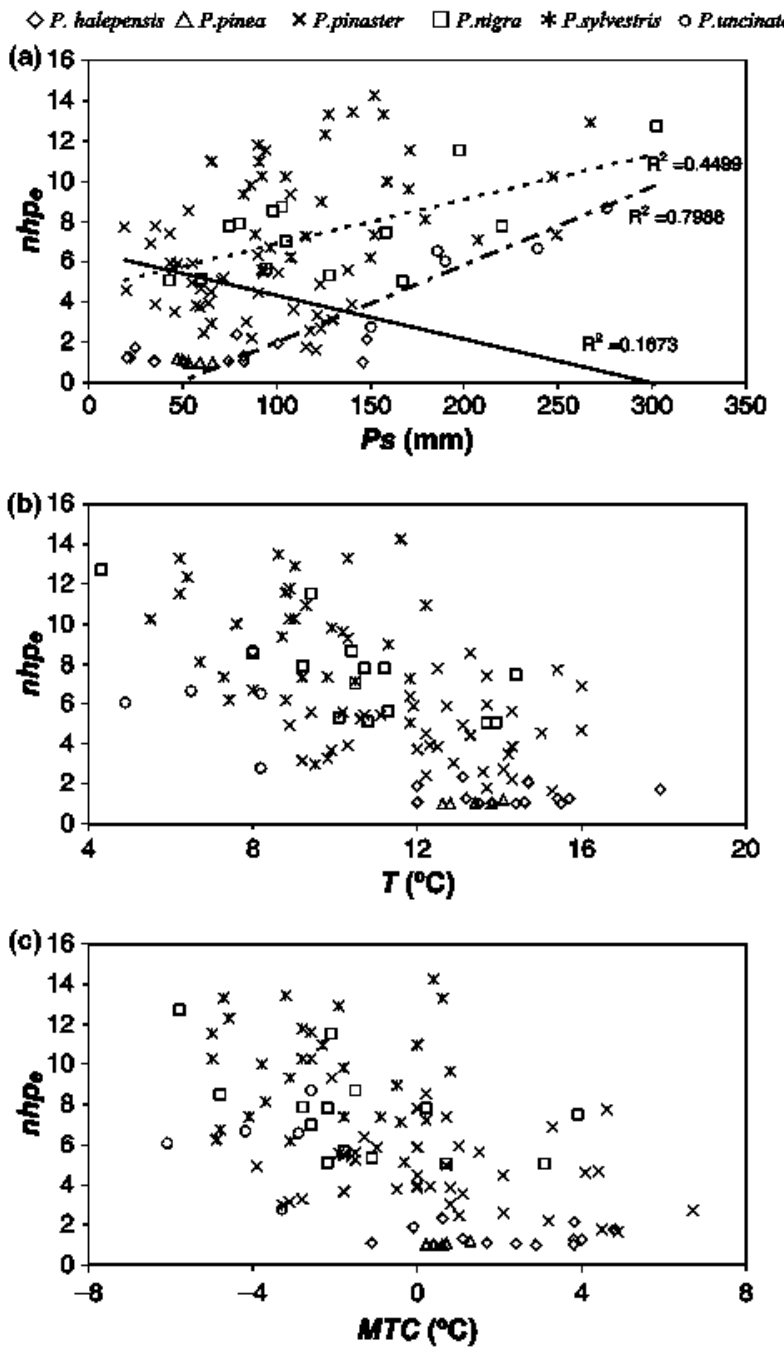

Fig. 1 Correlation between climatic variables ( $P$ s, summer precipitation; $T$, average annual temperature, and MTC average minimum of the coldest month) and the effective number of haplotypes $\left(n h \eta_{\mathrm{e}}\right.$ ) for populations of the six Iberian pines. Regression lines show significant $(P<0.05)$ correlations found at the intraspecific level (Pints pintister, continuous line; $P$, nigm, upper dotted line; and $P$. tencinata, lower dotted line), only observed for $P_{s}$. Species-level correlations (species pooled together) between $n h p_{e}$ and climatic variables were significant $(P<0.001)$, for all $P s$ (slope $=0.027, r=0.457), T$ (slope $=-0.783$, $r=-0.617$ ) and MTC (slope $=-0.689, r=-0.534$ ). Results for haplotypic richness ( $h /$ ip 15) were similar and are not reported.

variation in neutral genetic diversity and structure among Iberian pines, with cold-enduring mountain species showing substantially greater diversity than thermophilous taxa. There were no shared chloroplast haplotypes between species, even though hybridization has been reported for some of them: $P$. halepensis and $P$. pinaster (Schütt 1959) and $P$. sylvestris and P. uncinata (Wachowiak \& Prus-Glowacki 2008). The lack of remnant signatures of ancient genetic exchange in this study would suggest that hybridization has not been an important evolutionary force in this group of species within the Iberian Peninsula, in contrast to what has been suggested for other tree species, such as southern US yellow pines (Edwards-Burke et al. 1997) or European white oaks (Petit et al. 2002). It must be noted, however, that interspecific and intraspecific gene flow are expected to be inversely related (Petit \& Excoffier 2009). Thus, assuming that pollen dispersal is larger than seed dispersal, it would be risky to conclude from the present data that there is no DNA sharing across species at genome regions with maternal or biparental inheritance (see, e.g. Du et al. 2009).

The six Iberian pine species present marked differences in distribution, realized ecological niche and neutral genetic diversity. Observed genetic diversity differences across species were not consistent with general predictions relating distribution range and intraspecific variation: in general, higher levels of diversity are expected for species with larger distribution ranges, but our results do not fit this simple rule, at least within the confines of the Iberian Peninsula. For instance, Pimus uncinata has the smallest range and a scattered distribution, but its species-level diversity is among the highest observed, and much higher than two of the species ( $P$. pitzen and $P$, halepensis) with large distributions and continuous populations. Departures from this simple expectation have also been found in range-wide studies of some European conifers with a variety of molecular and biochemical markers, both organellar and nuclear (see review for the pine sextet in Supporting Information Table \$4). For example, range-wide studies by Bucci ef al. $(1998,2007)$ reported disparate levels of cpSSR diversity in $P$. halepensis and $P$. pinaster. This contrast can be interpreted as the result of very different historical demographic processes and range shifts for each species, both at the range-wide and at lberian Peninsula scales. Within the Iberian Peninsula, there is a well-documented presence of pine species throughout the Holocene (e.g. Carrión et al. 2003; García-Amorena et al. 2007). Climatic and demographic fluctuations could be expected to have affected each species differently, depending on their specific ecological requirements. Contrasting demographic histories, effective population sizes and consequent genetic processes (for example, genetic bottlenecks, founder effects, and drift), rather than contrasting present-day ranges, provide better explanations of the striking differences in genetic diversity among these species.

Even though the data presented here do not allow establishing causal links between species' climatic niche and neutral genetic diversity, the significant correlation between genetic diversity and current climatic range at 
Table 4 Linear regression analysis between $k h p_{e}$, the effective number of haplotypes per population (dependent variable), and $P_{s}$, summer precipitation (independent variable, measured in $\mathrm{mm}$ ) for each of the six Iberian pine species. The slopes of species with one common letter are not significantly different from each other

\begin{tabular}{|c|c|c|c|c|c|c|c|}
\hline \multirow[b]{2}{*}{ Species } & \multicolumn{3}{|l|}{ Intercept } & \multicolumn{4}{|l|}{ Slope } \\
\hline & Estimate & Std. error & $P$-value & Estimate & Std. error & P-value & Groups \\
\hline P. Inlepensis & 1.183 & 1.068 & 0.271 & 0.003 & 0.013 & 0.810 & $\mathrm{AB}$ \\
\hline P. pinea & 1.558 & 7.279 & 0.831 & -0.009 & 0.131 & 0.945 & $\mathrm{AB}$ \\
\hline P. pinaster & 6.479 & 0.794 & $<0.0001$ & -0.022 & 0.009 & 0.022 & A \\
\hline P. nigrt & 4.644 & 1.145 & $<0.0001$ & 0.022 & 0.008 & 0.005 & B \\
\hline P. syloestris & 8.211 & 0.979 & $<0.0001$ & 0.010 & 0.007 & 0.144 & B \\
\hline P. uncinata & -1.880 & 4.292 & 0.662 & 0.038 & 0.020 & 0.050 & B \\
\hline
\end{tabular}

the species level is consistent with the hypothesis that species-specific climatic requirements have played an important long-term role in shaping demography, and hence neutral genetic structure of Iberian pines. A similar dependency of neutral genetic patterns on climatic (Gutiérrez Larena et al. 2002) and edaphic (Alvarez et al. 2009) niche has been previously found in plants. The more thermophilous Mediterranean pines ( $P$. pined and $P$. halepensis) show extremely low levels of neutral genetic diversity, while the more cold-enduring pines (P. uncinata, P. syloestris and P. nigra) exhibit very high effective numbers of haplotypes.

Under the assumption that realized climatic niche reflects adaptive variation (i.e. that species and populations are locally adapted, as lberian pine common garden experiments suggest; Alía ef al. 1997, 2001; Chambel et al. 2007), we hypothesize that more thermophilous species have been subjected to more severe demographic fluctuations in the past, as a likely consequence of their susceptibility to recurrent glacial cold stages. Two caveats that must accompany this argument are: (a) that current realized niche might not be a good indicator of actual niche width, by virtue of incomplete range expansion after glaciations, and (b) that species' ecological requirements could have changed through the Holocene. Although the first caveat might translate into somewhat imprecise characterization of actual niche for individual species, it is dubious whether it would have substantially altered the relative positions of the species in the space of ecological-niche parameters and the impact on demography, with all of its ensuing consequences for genetic diversity. Relative to the second caveat, the potential confounding effects of adaptive evolution within species are difficult to predict, but the distributional patterns revealed by the available paleobotanical data do not seem to support Holocene changes in the relative temperature requirements of different species in the Iberian Peninsula (i.e. currently cold-tolerant pine species seem to have behaved as cold-tolerant species in the past, and analogously for thermophilic pines; Franco Múgica ef at. 2001; García-Amorena et al. 2007).

Currently, Iberian pines conform to a warm-stage distribution pattern, with P. uncinata, P. sylvestris and $P$. nigra sheltered at high elevation in mountain chains, and with $P$. halepensis and $P$. pinea growing mostly in low-elevation, warmer and drier areas (Fig. 2). In the Pyrenees, for example, $P$. uncinata grows at the timberline, with $P$. sylowstris and $P$. nigra at high to intermediate elevations, and $P$. halepensis and $P$. pinea in thermophilous basal areas. Throughout Quaternary climatic pulses, however, glacial-induced displacement of altitudinal belts would have enforced recurrent downhill and southward migrations in all six species, with contrasting demographic consequences. While coldenduring taxa would have been able to establish widespread woodlands in continental lowlands during full glacial stages (e.g. Robledo-Arnuncio et al. 2005), thermophilous species would have suffered further fragmentation and intense range contractions into smaller coastal refugia (both cold-stage distributional types are supported by the Iberian fossil record: Franco Múgica et al. 2001; Carrión et al. 2003; García-Amorena ef at. 2007). Across generations, periodic altitudinal migrations (including fast uphill displacements during the relatively shorter warm stages) would have allowed the maintenance of large effective population sizes and genetic variation in cold-tolerant species, but would have led to repeated bottlenecks and subsequent genetic diversity losses in the thermophilous species (e.g. Vendramin ef al. (2008) for P. pinea). In addition, bottlenecks in thermophilous pines might have been exacerbated by higher historical recurrence and intensity of forest fires in Mediterranean environments (Lloret ef al 2003; Thompson 2005), though we still lack information on the population genetic consequences of forest fires.

An interesting question for future research, in particular for testing the above hypothesis that 


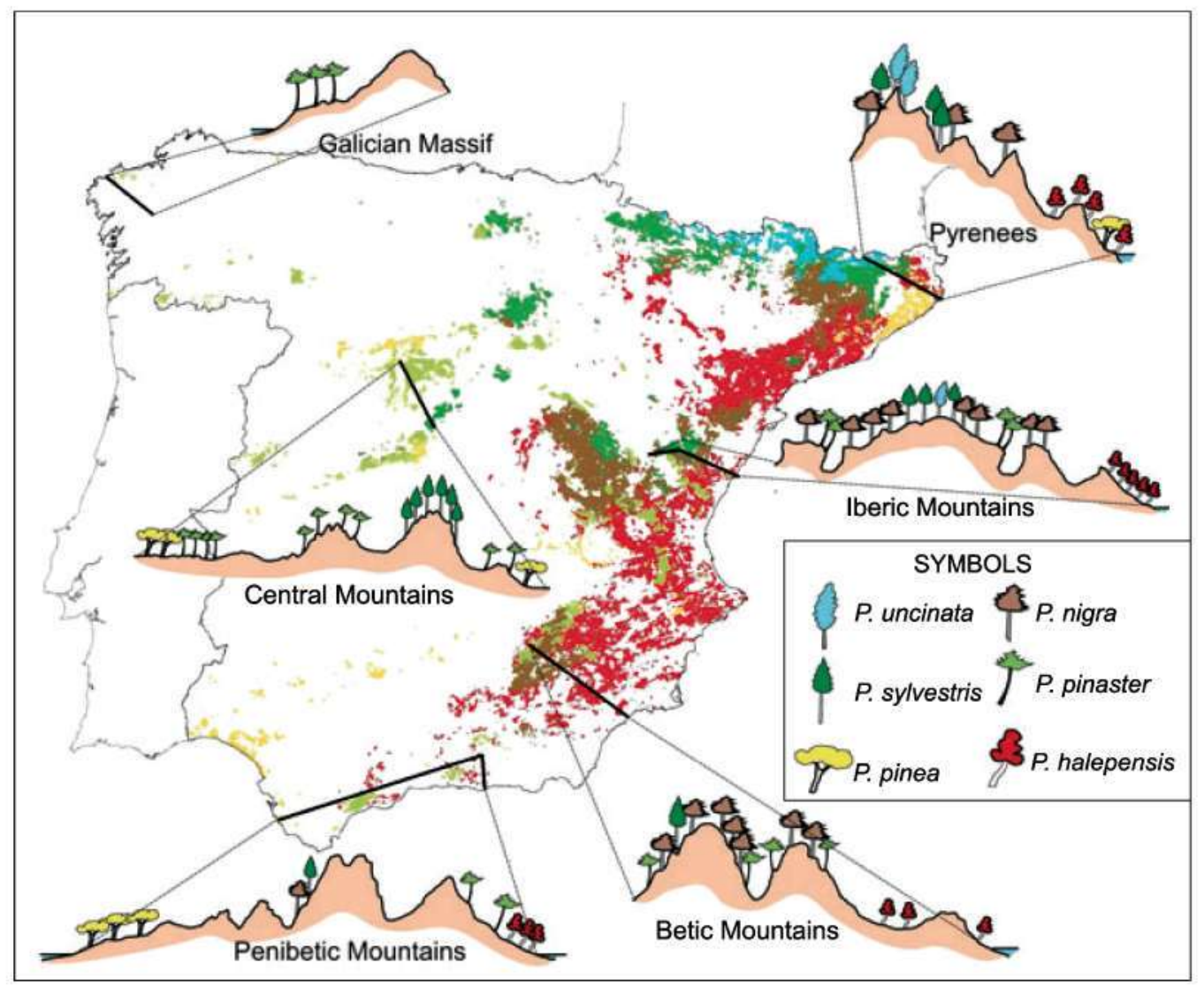

Fig. 2 Current altitudinal distribution of the six Iberian pine species in different mountain chains.

warm-demanding species have been more affected by repeated glacial periods, is to what extent has the width of coastal refugia changed as a consequence of sea-level fluctuations associated to climate changes. Lowered sea levels during glacial pulses could have exposed new suitable refugial habitats for thermophilic taxa (Provan \& Bennett 2008), mitigating cold-stage range contractions. The area under oceanic influence (the land-sea ecotone), however, would have been simultaneously displaced towards the sea, so knowing whether the actual width of mild costal habitats free from continental climatic extremes would actually have been increased, and by how much, will probably require detailed investigation of regional surface and coastal shelf topography.

Apart from observed differences in genetic diversity levels across species, the evidence of phylogeographic structure for cold-enduring mountain pines but not for thermophilous pines (as indicated by $R_{\mathrm{ST}}$ values significantly larger than $F_{\mathrm{ST}}$ values; Table 3 ), would also be consistent with the hypothesis of a less stable longterm demography in thermophilous species. On the other hand, there was a significant positive correlation between summer precipitation and genetic diversity at the population level for two of the mountain pines ( $P$. nigra and $P$. uncinata), which might suggest that mountain populations inhabiting regions with more regular precipitation would have enjoyed larger longterm effective sizes and demographic stability. An opposite trend was found among populations of Mediterranean P. pinaster, which is also consistent with its known demographic history. Unlike mountain pines, which maintained large stable populations in both peripheral and central Iberian regions throughout glacial periods, $P$. pinaster seems to have sheltered in multiple relatively-small refugia during cold stages, including mountainous areas in southeastern Spain (Bucci et al. 2007); after the last glacial maximum, the recolonization of most Iberian regions by this species followed a southeast-northwest direction that coincides with the Mediterranean-Eurosiberian climatic gradient, which could explain the negative association between summer-drought and genetic diversity (Salvador et al. 2000).

Other factors can also be invoked to explain the observed differences in neutral genetic diversity among the six pine species, such as human intervention, differences in mutation rates, and time and pattern of initial 
establishment of the species in the Iberian Peninsula. There is no obvious reason, however, to expect any of these (non-mutually exclusive) factors to result in the observed association between climatic range and neutral genetic diversity. Human exploitation and management have been similarly intense in both cold-tolerant, highly-diverse ( $P$. sylitestris, $P$. nigra) and thermophilous, genetically depauperate ( $P$. pinea, $P$. halepensis) species. In addition, one species with relatively high diversity, $P$. pinaster, is the main pine crop in this range. Moreover, human impact on neutral diversity of Mediterranean conifers seems to have been low (Fady-Welterlen 2005). It is also unlikely that variation in mutation rates among species would have generated the observed diversity differences, since all six species were screened at the same chloroplast SRR regions and microsatellite motifs in these regions have similar numbers of repeats across species (Supporting Information Appendix S2), and since observed differences are consistent with other results (albeit partial) in the region across different type of markers (e.g. Fallour ef at. 1997 reported very low levels of allozyme polymorphism in P. pinen and Prus-Glowacki et al. 2003 very high in some $P$. syloestris populations, while intermediate levels have been found in P. pinaster, Salvador et al. 2000; see also Table $\mathbf{S 4}$ in Supporting Information).

The impact of initial establishment in the region is more complex to assess, partly because of the scarcity of data. It is generally accepted that mountain pines ( $P$. uncinata, $P$. sylvestris and $P$.nigra) are Tertiary relicts with a continued presence in the Iberian Peninsula throughout the Quaternary. There are also fossil and pollens records for $P$. pinaster and $P$. pinea, dating back ca. $30000 \mathrm{BP}$ and $49200 \mathrm{BP}$, respectively (Salvador ef al. 2000; Vendramin ef at. 2008; and references therein). By contrast, it is unclear whether $P$. halepensis was present in the Iberian Peninsula before the early Holocene (Gómez et al. 2005 and references therein; Grivet ef al. 2009). Assuming that $P$. halepensis actually arrived in the Iberian region more recently than the other pines, it could be hypothesized that its extremely low diversity is the result of recent founder effects and genetic bottlenecks associated with colonization. It is dubious, however, that a colonization wave alone could have produced such a depletion of genetic diversity in this species, given the low (Comps et al. 2001) to moderate (Cwynar \& MacDonald 1987) reductions in allelic richness reported in the few well-documented studies of rapid tree expansions and the currently wide distribution of $P$. halepentis across the Iberian Peninsula. It seems reasonable then to assume periodic demographic collapses during glacial cold stages, in addition to a founder effect during a relatively recent (albeit preHolocene) colonization of the Iberian Peninsula, to explain the very low levels of haplotypic diversity found in this species.

Severe and rapid changes in the demography and distribution of plant species have been forecasted for coming decades in Europe if rapid global warming continues, especially in the Iberian Peninsula and other Mediterranean mountainous regions (Thuiller et al. 2005). Mountain species or populations unable to cope with increasing heat and drought conditions, and with the consequential increase in intensity and recurrence of forest fires, will be threatened, unless rapid migration brings them to suitable habitat. Migration would involve further uphill displacements in mountain species. The already small populations of timberline $P$. uncinata could suffer further severe habitat contraction, diversity losses and population divergence through demographic bottlenecks, paralleling those experienced by some mountain conifer isolates in North America (Ledig ef at. 1997; Oline ef at. 2000). By contrast, the other two mountain pines, $P$. syloestris and $P$. nigra, presently form widespread populations that rarely reach the crests of the mountain chains, which should enable further uphill migration and the maintenance of relatively large effective population sizes (Robledo-Arnuncio et al. 2005). Climate warming can be expected to have more positive demographic and genetic effects on Mediterranean $P$. pinea and $P$. halepentsis, as well as for the ecologically diverse $P$. pinaster, with an eventual expansion of their distribution ranges enabling a gradual recovery of their genetic diversity. Any speculative prediction of this kind, of course, could be altered by interspecific competition (also subject to climate change) or by unaccounted interactions among abiotic factors.

Cross-species patterns of neutral genetic variation provide indirect clues on climate-species relationships, especially valuable in forest trees, the longevity of which hampers direct experimental approaches to the problem. Future comparative studies across species would benefit from the combination of neutral genetic data, useful for demographic inference, with quantitative and gene sequence information of adaptive significance, necessary for a better understanding of the evolutionary consequences of the interplay between environmental change and species biology.

\section{Acknowledgements}

We warmly thank Ana Álvarez Linarejos, Luis Diaz Díez and Carmen García Barriga for invaluable and dedicated assistance in molecular analyses, and Jesús de Miguel and David Sánchez for producing Fig. 2. We extend our thanks to Rémy Petit and three anonymous reviewers for constructive comments. This work was supported by projects from the European Union 
(EVOLTREE Network of Excellence, http://www.evoltree.eu), Spanish Ministry of Environment (CC03-048 and AEG06-054), Sparish National Research Foundation (REN 2000-1617-GLO) and Madrid Autonomous Region (07M0004-2001). JJRA was supported by a Ramón y Cajal research fellowship from the Spanish 'Ministerio de Ciencia e Innovación'. PES was supported by USDA/NJAES-17111, NSF-DEB-0211430, and NSF-DEB-0514956.

\section{References}

Afzal-Rafii Z, Dodd RS (2007) Chloroplast DNA supports a hypothesis of glacial refugia over postglacial recolonization in disjunct populations of black pine (Pinus nigra) in western Europe. Molecular Ecology, 16, 723-736.

Alía R, Moro J, Denis JB (1997) Performance of Pinus pinaster provenances in Spain: interpretation of the genotype by environment interaction. Contindith Joumal of Forest Research, 27, 1548-1559.

Alía R, Moro-Serrano J, Notivol E (2001) Genetic variability of Scots pine (Pinus sylvestris) provenances in Spain: growth traits and survival. Silw Fennica, 35, 27-38.

Alvarez N, Thiel-Egenter C, Tribsch A et al. (2009) History or ecology? Substrate type as a major driver of spatial genetic structure in Alpine plants. Ecology Letters, 12, 632640 .

Anderson BG, Borns HW (1994) The ice nge World: An Introduction to Quatemary History and Research With Emphasis on North America and Northem Europe During the Last 2.5 Million Years. Scandinavian University Press, Oslo.

Barbéro M, Loisel R, Quézel P, Richardson DM, Romane F (1998) Pines of the Mediterranean Basin. In: Ecology and Biogeography of Pinus (ed. Richardson DM). pp. 153-170, Cambridge University Press, Cambridge.

Benito Garzón M, Sánçhez de Dios R, Sainz Ollero H (2008) Effects of climate change on the distributions of Iberian forest. Applied Vegetation Science, 11, 169-178.

Bucci G, Anzidei M, Madaghiele A, Vendramin GG (1998) Detection of haplotypic variation and natural hybridization in halepensis-complex pine species using chloroplast simple sequence repeats (SSR) markers. Molechlitr Ecology, 7, 16331643.

Bucci G, González-Martínez SC, Le Provost G ef al. (2007) Range-wide phylogeography and gene zones in Pinus pinaster Ait. revealed by chloroplast microsatellite markers. Molecular Ecology, 16, 2137-2153.

Carrión JS, Walker MJ, Legaz A, Chain C, Lopez A (2003) Glacial refugia of temperate, Mediterranean and Ibero-North African flora in south-eastern Spain: new evidence from cave pollen at two Neanderthal man sites. Global Ecology and Biogeogriphy, 12, 119-129.

Chambel MR, Climent J, Alía R (2007) Divergence among species and populations of Mediterranear pines in biomass allocation of seedlings grown under two watering regimes. Annits of Forest Science, 64, 87-97.

Cheddadi R, Vendramin GG, Litt $T$ et al. (2006) Imprints of glacial refugia in the modern genetic diversity of Pinus syloestris. Global Ecology and Biogeography, 15, 271-282.

Comes HP, Kadereit JW (1998) The effect of Quaternary climatic changes on plant distribution and evolution. Trends in Plant Science, 3, 432-438.
Comps B, Gömöry D, Letouzey J, Thiébaut B, Petit RJ (2001) Diverging trends between heterozygosity and allelic richness during postglacial colonization in the European beech. Genetics, 157, 389-397.

Cwynar LC, MacDonald GM (1987) Geographical variation of lodgepole pine in relation to population history. The American Naturalist, 129, 463-469.

Dellaporta SL, Wood J, Hicks JB (1983) A plant DNA minipreparation: version II. Plant Molecular Biology Reporter, 1, 19-21.

Doyle JJ, Doyle JL (1990) Isolation of plant DNA from fresh tissue. Focus, 12, 13-15.

Du FK, Petit RJ, Liu JQ (2009) More introgression with less gene flow: chloroplast vs. mitochondrial DNA in the Picea asperita complex in China, and comparison with other Conifers. Molectilar Ecology, 18, 1396-1407.

Edwards-Burke MA, Hamrick JL, Price RA (1997) Frequency and direction of hybridization in sympatric populations of Pinus taeta and P. echinata (Pinaceae). American Journal of Botitry, 84, 879-886.

El Mousadik A, Petit RJ (1996) High level of genetic differentiation for allelic richness among populations of the argan tree [Argania spinosa (L) Skeels] endemic to Morocco. Theoretical and Applied Genetics, 92, 832-839.

Excoffier L, Smouse PE, Quattro JM (1992) Analysis of molecular variance inferred from metric distances among DNA haplotypes-application to human mitochondrial DNA restriction data. Genetics, 131, 479-491.

Fady-Welterlen B (2005) Is there really more biodiversity in Mediterranean forest ecosystems? Titxon, 54, 905-910.

Fallour D, Fady B, Lefèvre F (1997) Study on isozyme variation in Pinus pirea L.: evidence for low polymorphism. Silvae Genetica, 46, 201-207.

Franco Múgica F, García Antón M, Maldonado Ruiz J, Morla Juaristi C, Sainz Ollero H (2001) The Holocene history of Pinus forests in the Northern Spanish Meseta. The Holocene, 11, 343-358.

García-Amorena I, Gómez Manzaneque F, Rubiales JM ef al (2007) The Late Quaternary coastal forests of western Iberia; a study of their macroremains. Pitacogeography, Paticodintitology, Paticoecology, 254, 448-461.

Gernandt DS, Lopez GG, Garcia SO, Liston A (2005) Phylogeny and classification of Pinus. Taxon, 54, 29-42.

Gómez A, Lunt DH (2007) Refugia within refugia: patterns of phylogeographic concordance in the Iberian Peninsula. In:Phylogeogriphy of Southern Europerth Reftigia (eds Weiss S, Ferrand N). PF. 155-188, Springer, Dordrecht.

Gómez A, Vendramin GG, Gonzalez-Martinez SC, Alia R (2005) Genetic diversity and differentiation of two Mediterranean pines (Pirus hitepensis Mill. and Pinus piraster Ait.) along a latitudinal cline using chloroplast microsatellite markers. Diversify and Distributions, 11, 257-263.

Gonzalo J (2007) Phytoclimatic Analysis of the Spanish Peninsula. Update and Geostntistical Analysis. [Diaghosis Fitoclintatica de th Españit Peninsular. Actutización y Anatisis Geoestadístico Aplicatoj. PhD Thesis. Universidad de Valladolid, Spain.

Grivet D, Sebastiani F, González-Martínez SC, Vendramin GG (2009) Patterns of polymorphism resulting from long-range colonization in the Mediterranean conifer Aleppo pine. New Phytologist, 184, 1016-1028. 
Gutiérrez Larena B, Fuertes Aguilar J, Nieto Feliner G (2002) Glacial-induced altitudinal migrations in Ameria (Plumbaginaceae) inferred from patterns of chloroplast DNA haplotype sharing. Molecular Ecology, 11, 1965-1974.

Hampe A, Petit RJ (2005) Conserving biodiversity under climate change: the rear edge matters. Ecology Letters, 8, 461467

Hamrick JL (2004) Response of forest trees to global environmental changes. Forest Ecology and Management, 197, 323-335.

Hardy OJ, Charbonnel N, Fréville H, Heuertz M (2003) Microsatellite allele sizes: a simple test to assess their significance on genetic differentiation. Gentics, 163, 14671482.

Heuertz M, Teufel J, González-Martínez SC et al. (2010) Geography determines genetic relationships between Pints uncinth Ram., Pints mitgo Turra and Pinus rotundatit Link (mountain pines). Journal of Biogeography, 37, 541-556.

Hewitt GM (2000) The genetic legacy of the Quaternary ice ages. Niture, 405, 907-913.

IPCC (2001) Climate Change 2001: The Scientific Bosis. Contribution of Working Group I to the Third Assessment Report. of the Intergovemmental Panel on Clmate Change. Cambridge University Press, Cambridge.

Jost L (2008) $G_{S T}$ and its relatives do not measure differentiation. Molecular Ecology, 17, 4015-4026.

Ledig FT, Jacob-Cervantes V, Hodgskiss PD, Eguiluz-Piedra T (1997) Recent evolution and divergence among populations of a rare Mexican endemic, Chihuahua spruce, following Holocene climatic warming. Evolution, 51, 1815-1827.

Liepelt S, Bialozyt R, Ziegenhagen B (2002) Wind-dispersed pollen mediates postglacial gene flow among refugia. Proceedings of the National Acatemy of Sciences of the USA, 99, 14590-14594.

Lloret F, Pausas JG, Vilà M (2003) Response of Mediterranean plant species to different fire regimes in Garraf Natural Park (Catalonia, Spain): field observations and modelling predictions. Plant Ecology, 167, 223-235.

Médail F, Diadema K (2009) Glacial refugia influence plant diversity patterns in the Mediterranean Basin. Jotumal of Biogeograpin, 36, 1333-1345.

Milliken GA, Johnson DE (2001) Annlysis of Messy Data, Volume III: Analysis of Cooariance. Chapman \& Hall, New York.

Myers N, Mittermeier RA, Mittermeier CG, da Fonseca GAB, Kent J (2000) Biodiversity hotspots for conservation priorities. Nature, 403, 853-858.

Navascués M, Emerson BC (2005) Chloroplast microsatellites: measures of genetic diversity and the effect of homoplasy. Molecultr Ecology, 14, 1333-1341.

Nei M, Chesser R (1983) Estimation of fixation indices and gene diversities. Annals of Human Genetics, 47, 253-259.

Newton AC, Allnutt TR, Gillies ACM, Lowe AJ, Ennos RA (1999) Molecular phylogeography, intraspecific variation and the conservation of tree species. Trends in Ecology and Evolution, 14, 140-145.

Nielsen R, Tarpy DR, Reeve HK (2003) Estimating effective paternity number in social insects and the effective number of alleles in a population. Molecular Ecology, 12, 3157-3164.

Oline DK, Mitton JB, Grant MC (2000) Population and subspecific genetic differentiation in the Foxtail pine (Pirus balfouriam). Evolution, 54, 1813-1819.
Petit RJ, Excoffier L (2009) Gene flow and species delimitation. Trends in Ecology and Evolution, 24, 386-393.

Petit RJ, Csaikl UM, Bordács $S$ et al. (2002) Chloroplast DNA variation in European white oaks: phylogeography and patterns of diversity based on data from over 2,600 populations. Forest Ecology and Minagement, 156, 5-26.

Petit RJ, Aguinagalde I, de Beaulieu JL et at. (2003) Glacial refugia: hotspots but not melting pots of genetic diversity. Science, 300, 1563-1565.

Petit RJ, Hu FS, Dick CW (2008) Forests of the past: a window to future changes. Science, 320, 1450-1452.

Phillips SJ, Anderson RP, Schapired RE (2006) Maximum entropy modeling of species geographic distributions. Ecological Modelling, 190, 231-259.

Price RA, Liston A, Strauss SH (1998) Phylogeny and systematics. In:Ecology and Biogeography of Pinus (ed. Richardson DM). pp. 49-68, Cambridge University Press, Cambridge.

Provan J, Bennett KD (2008) Phylogeographic insights into cryptic glacial refugia. Trends in Ecology and Evolntion, 23, 564-571.

Provan J, Powell W, Hollingsworth P (2001) Chloroplast microsatellites: new tools for studies in plant ecology and evolution. Trends in Ecology and Evolution, 16, 142-148.

Prus-Glowacki B, Stephan BR, Bujas E, Alía R, Marciniak A (2003) Genetic differentiation of autochtonous populations of Pinus sylvestris (Pinaceae) from the Iberian Peninsula. Plant Systematics and Evolition, 239, 55-66.

Robledo-Arnuncio JJ, Collada C, Alía R, Gil L (2005) Genetic structure of montane isolates of Pinus sylvestris L. in a Mediterranean refugial area. Journt of Biogeography, 32, 595-605.

Salvador L, Alía R, Agúndez D, Gil L (2000) Genetic variation and migration pathways of maritime pine (Pinus pinaster Ait) in the Iberian Peninsula. Theoretical and Apnlied Genetics, 100, $89-95$.

Schütt P (1959) Züchtung mit Kiefern Teil 2. Kreuzungen, Resistenzzüchtung und Zytologie. Mitt. Bundesforsch. Forstund Holzwirt. Forstgenetik und Forstpflanzenzüchtung, 42, $1-40$.

Taberlet P, Fumagalli L, Wust-Saucy AG, Cosson JF (1998) Comparative phylogeography and postglacial colonization routes in Europe. Molecular Ecology, 7, 453-464.

Tapias R, Climent J, Pardos JA, Gil L (2004) Life histories of Mediterranean pines. Plant Ecology, 171, 53-68.

Thompson JD (2005) Plint Evolution in the Mediterranean. Oxford University Press, New York.

Thuiller W, Lavorel S, Araujo MB, Sykes MT, Prentice C (2005) Climate change threats to plant diversity in Europe. Proceedings of the National Academy of Sciences of the USA, 102, $8245-8250$.

Vendramin GG, Lelli L, Rossi P, Morgante M (1996) A set of primers for the amplification of 20 chloroplast microsatellites in Pinaceae. Molecular Ecology, 5, 595-598.

Vendramin GG, Fady B, González-Martínez SC ef al. (2008) Genetically depauperate but widespread: the case of an emblematic Mediterranean pine. Evolution, 62, 680-688.

Wachowiak W, Prus-Glowacki W (2008) Hybridisation processes in sympatric populations of pines Pinus syloestris L., P. migo Turra and P. uliginosn Neumann. Plant Systematics and Evolution, 271, $29-40$.

Wang XR, Tsumura $Y$, Yoshimaru H, Nagasaka K, Szmidt AE (1999) Phylogenetic relationships of eurasian pines (Pinus, 
Pinaceae) based on chloroplast RBCL, MATKV, RPL20RPS1 8 spacer, and TRNV intron sequences. Amterican Jourral of Botamy, 86, 1742-1753.

Whitham TG, Bailey JK, Schweitzer JA et al. (2006) A framework for community and ecosystem genetics: from genes to ecosystems. Nature Revietws Gentics, 7, 510-523.

A.S. is interested in the study of genetic diversity, hybridization phenomena and conservation genetics in forest tree species. J.J.R.A. is a population geneticist with special interest in dispersal estimation methods and the evolutionary consequences of gene flow. S.C.G.M. has broad interests in population genetics and genomics of forest trees and Mediterranear plant endemics. P.S. has interests in population genetics and biostatistical modelling. R.A. is interested in population variation of Mediterranean pines and the use and conservation of genetic resources.

\section{Supporting Information}

Additional supporting information may be found in the online version of this article.

Table S1 Average and standard deviations (in brackets) of climatic variables across sampled populations of the six Iberian pines

Table S2 Genetic diversity of the six Iberian pine species at six cPSSR marker regions
Table S3 Parallelism tests (Milliken \& Johnson 2001) of regression lines between population level genetic diversity and population climatic variables for the six Iberian pine species

Table S4 Authors' selection of biochemical and molecular marker studies (not exhaustive), with a focus on recent studies in the western Mediterranean, reporting levels of genetic diversity of the six pine species present in the Iberian Peninsula. NP, number of populations; NL, number of loci; NA, data not available

Fig. S1 Location of sampled populations of the six native Iberian pines.

Fig. S2 Importance of nine climatic variables to predict the actual distribution of Iberian pines. Jackknife procedure, from Maxent Software (Phillips te al. 2006), applied to a $1 \times 1 \mathrm{~km}$ grid of presence of the species obtained from the 3rd Spanish National Forest Inventory.

Appendix S1 Investigation of potential unequal sample size biases in cross-species diversity comparisons.

Appendix S2 Direct sequencing of common variants for Pt36480, Pt87268, Pt71936 chloroplast microsatellite markers.

Please note: Wiley-Blackwell are not responsible for the content or functionality of any supporting information supplied by the authors. Any queries (other than missing material) should be directed to the corresponding author for the article. 